\begin{tabular}{c}
\hline RECORDS OF PHARMACEUTICAL \\
AND BIOMEDICAL SCIENCES
\end{tabular}

\title{
Anticancer potential of Moringa peregrina
}

\author{
Maged Mohamed Maher Abou-Hashem a, Ahmed Mohamed Abd EL-Mawgoud *b \\ Dina Mohamed Abo-elmatty ${ }^{\mathrm{c}}$, Noha Mostafa Mesbah ${ }^{\mathrm{c}}$ \\ ${ }^{a}$ Faculty of Pharmacy, Pharmacognosy Department, Zagazig University, Zagazig, 44511, Egypt, ${ }^{b}$ Egyptian \\ International Pharmaceutical Industries Co (EIPICO), Tenth of Ramadan city, 44629, Egypt., ${ }^{c}$ Faculty of \\ Pharmacy, Biochemistry Department, Suez Canal University, Ismailia, 41522, Egypt.
}

Received on: 28. 05. 2020

Revised on: 06. 09. 2020

Accepted on: 10. 09. 2020

*Correspondence Author:

Tel: +201004199076

E-mail address:

awaditech@gmail.com

\begin{abstract}
Cancer is an advanced disease characterized by numerous etiologies and multiple stages evoked by the deregulation in genetic and epigenetic programs via many factors like hormonal perturbation, microbial infections and chemical carcinogenesis. Once cells become cancerous, they still divide forever with none response of sign programmed cell death or senescence. Treatment relies on radiotherapy and chemotherapy that target cells with fast division. These treatments cause numerous side effects on normal cells division. Natural products have continually and historically been studied for promising new leads in pharmaceutical development. Several plant parts are utilized in traditional medicine because they are easily available in rural areas and less expensive compared to new synthetic therapeutic drug. Moringa peregrina (M. peregrina), which belongs to the monogenic Moringaceae family, offers these advantages. Moringa trees possess different medicinal and nutritional value. This current review focuses on the chemical and biological properties of $M$. peregrina as a promising source of anti-cancer agent(s).
\end{abstract}

Keywords: Moringa peregrina; Anti-cancer.

\section{Introduction}

Cancer is a cluster of diseases involving abnormal cell growth with the potential to spread to extra parts of the body (Anand et al., 2008). They form a subset of neoplasms. A neoplasm or tumor is a cluster of cells that have undergone unregulated growth, and will regularly produce a mass or lump, however may be spread diffusely (Kravchenko et al., 2009). Not all tumors are cancerous; benign tumors do not invade other parts of the body (Pan et al., 2019).
Cancer is amongst the major noncommunicable diseases causing death worldwide. Cancer alone accounts for $21.7 \%$ of all noncommunicable diseases (Tiloke et al., 2016).

\section{Hallmarks of Cancer}

The hallmarks of cancer include sustaining proliferative signaling, evading growth suppressors, genome instability and mutation, enabling replicative immortality, tumor-promoting inflammation inducing angiogenesis, avoiding immune destruction, activating invasion and metastasis and resisting cell death (apoptosis). 


\section{Apoptosis}

Apoptosis is a form of programmed cell death (cell suicide), the mechanism by which cells are programmed to die within the event they become damaged. Cancer cells are characteristically able to bypass this mechanism. Cells can self-destruct; a process referred to as apoptosis. This is required for organisms to grow and develop properly, for maintaining tissues of the body, and is additionally initiated when a cell is damaged or infected. Cancer cells, however, lose this ability; while cells may become grossly abnormal, they do not apoptose (Hanahan and Weinberg, 2011).

\subsection{Characteristics of apoptosis}

Morphological changes of apoptosis include chromatin condensation, nuclear fragmentation, cell shrinkage, late mitochondrial disintegration, membrane blebbing, cell shrinkage and eventually phagocytosis (Ouyang et al., 2012; Wong, 2011). Biochemical changes in apoptosis are DNA fragmentation, caspase activation, poly (ADPribose) polymerase proteolysis (Giansanti et al., 2011), phosphatidylserine externalization, cleavage of intracellular substrates by enzymes and recognition by phagocytic cells (Ouyang et al., 2012).

\subsection{Apoptosis pathways}

\subsubsection{Intrinsic pathway}

The intrinsic pathway is initiated internally by stimuli such as stress, hypoxia, oxidative stress and DNA damage. This leads to mitochondrial disruption, increased mitochondrial permeability and the release of apoptotic proteins (Wong, 2011). The apoptosome is formed when cytochrome $\mathrm{c}$ is released into the cytoplasm and binds to Apoptotic Protein Activating Factor 1 (APAF-1). This results in caspase cascade activation (Wen et al., 2012). When caspase 8 is triggered, it cleaves pro caspase 3 to form caspase 3, which in turn cleaves other caspases (Ghavami et al., 2009). Mitochondria also release nucleases that degrade DNA and the cellular fragments are engulfed by phagocytes to complete apoptosis (Giansanti et al., 2011).

\subsubsection{Extrinsic pathway}

The extrinsic pathway is initiated by cell death signals which result from death ligands binding to specific death receptors.
Common death receptors include tumor necrosis factor-alpha (TNF- $\alpha$ ) and Fas and their ligands TNF- $\alpha$ L and Fas-L (Ola et al., 2011). Death receptors have death domains that recruit adapter proteins such Fas Associated Death Domain Protein (FADD) (Ashkenazi, 2002). Death inducing signaling complex (DISC) is formed by trimerization of death ligands, and induction of death receptor oligomerization, which provides a binding site for adaptor protein (Yan and Shi, 2005). DISC also initiates the activation of caspase 8 which initiates apoptosis (Bellail et al., 2010). The two apoptotic pathways are diagramed in Figure 1.

\section{Treatment of Cancer}

Cancer is treated by surgery, chemotherapy, radiotherapy, hormonal therapy, and targeted therapy (including immunotherapy such as monoclonal antibody therapy). The selection of therapy depends upon the placement, grade of the tumor, the stage of the disease and the general state of the patient (performance status). Variety of experimental cancer treatments also are under development (Palumbo et al., 2013).

The problem of unacceptable side effects like low specificity, dose-related toxicity and the recurrence of patient tumors because of prevalence of drugresistant cells remains hold block to achievement of anti-cancer chemotherapy. Cisdiamminedichloroplatinum (II) or cisplatin is highly effective in treating cervical carcinoma, but have neurotoxic effects on the central nervous system and the peripheral nervous system. The foremost commonly observed adverse-effects include moderate myelosuppression, emesis, nephrotoxicity, ototoxicity and neurotoxicity. More rare adverse-effects include ophthalmological effects, seizures and autonomic neuropathy. Therefore, searching for new chemotherapeutic agents has refocused on natural products, leading to the discovery of some new bioactive compounds (Ng et al., 2011).

\section{Medicinal plants as sources of anticancer drugs}

For generations, medicinal plants have been used as a primary source for the treatment of diseases globally (Karunamoorthi et al., 2013). 


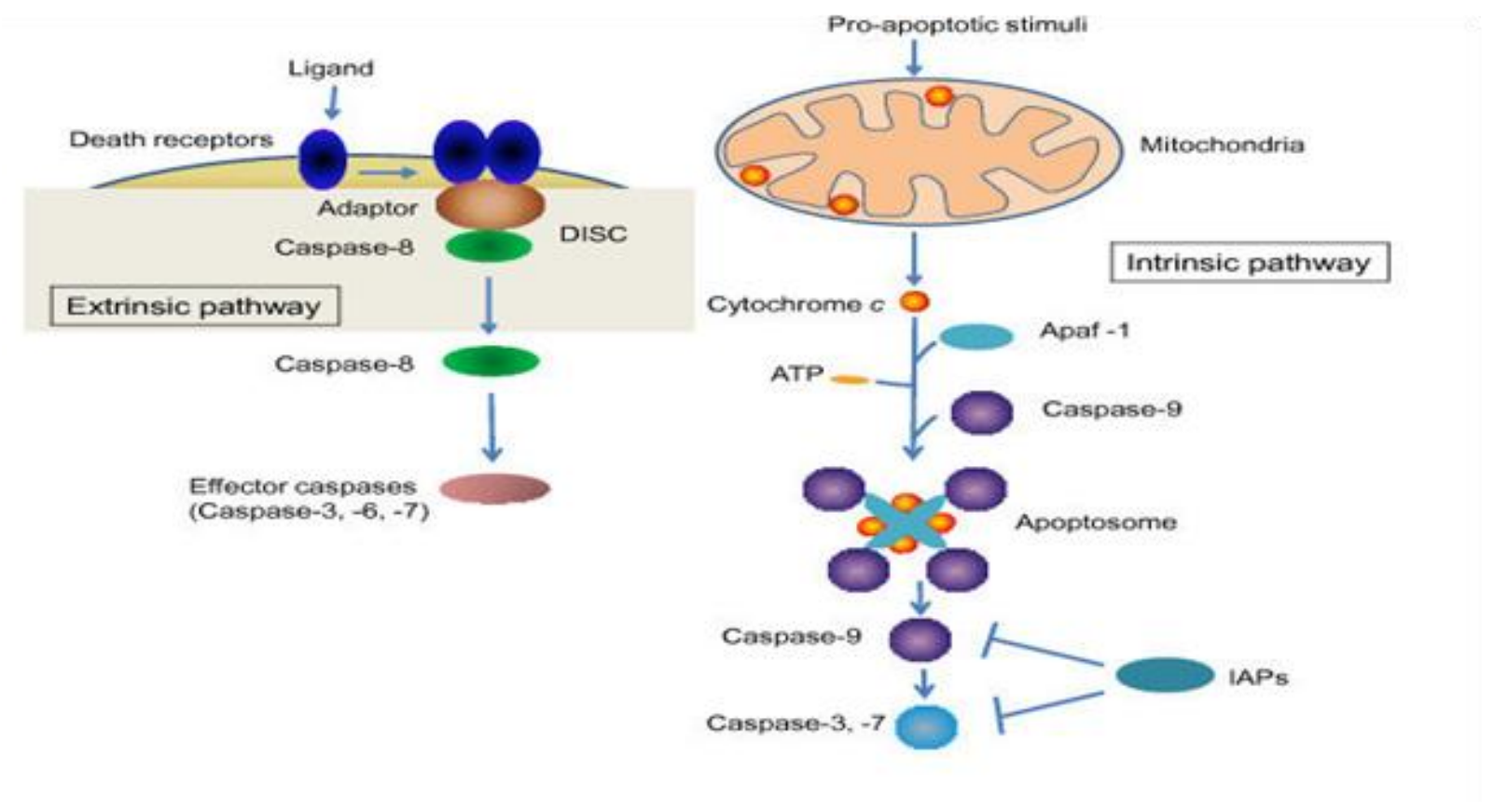

Figure 1: Diagram for two major apoptosis pathways (Li and Sheng, 2012).

Despite the increase usage of modern medicine, some countries still rely on herbal medicine due to high cost of modern drugs. According to the WHO, $70 \%$ of the world population is using herbal medicine as alternative or mainstay therapeutic treatment for diseases (Kaur and Arora, 2009). The increased interest in scientific research on herbal medicine is due to their documented antioxidant, antimicrobial, anti-diabetic and anticancer effects (Rafieian-Kopaei, 2012). Up to $50 \%$ of modern drugs are derived from plants and their derivatives (Pan et al., 2013).

Medicinal plants contain phytochemicals such as carotenoids, polyphenols, alkaloids, saponins, tannins and vitamins as well as many other constituents. Most of the phytochemicals have antioxidant activity and can decrease the risk of developing diseases. In addition, these phytochemicals exhibit anti-inflammatory, antimutagenic and anticancer properties (Mothana et al., 2009). Polyphenols are a class of chemicals that include flavonoids, phenolic acids, tannins and stilbenes. Recently, dietary polyphenols such as flavonoids and phenolic acids have been of interest due to their health benefits such as antioxidants, anticancer, anti-inflammatory and chemopreventive properties (Ramos, 2007).

\section{Family: Moringaceae}

The Moringaceae is a monotype family of sole genus Moringa with 13 species. Moringa trees are important food commodity as almost all plant parts are edible and consumed as nutritive vegetable in many countries. Many plants of this family are used in traditional medicine globally for the treatment of various illnesses (Al-Owaisi et al., 2014).

This family also contains the most widely known species $M$. oleifera Lam., known as drumstick tree (Awodele et al., 2012). Miracle tree (Moringa peregrina) is known in Arabic as "Habb El Yasar, Habb El Pan" and the seeds are known as "Habba Ghalia" and it is a very fast growing tree or shrub (Said-Al Ahl et al., 2017). It is grown in many areas of the world like Northeastern tropical Africa, Madagascar and Arabia (Al-Owaisi et al., 2014).

\subsection{Traditional uses of Moringa}

Almost all parts of Moringa peregrina, viz., flowers, fruits and roots are edible, and have long been consumed as vegetable and used to treat many diseases such as abdominal tumors, hysteria, scurvy and paralytic attacks (El Baky and ElBaroty, 2013). 
The leaf extract of $M$. peregrina is rubbed over skin to treat skin rashes in folk medicine. The juice from the bark of $M$. peregrina is used as a disinfectant to speed up wound healing. In the Northern Oman, oil extracted from the pods is used in treatment of infantile paralysis or convulsions. In Egypt, it is used locally to treat slimness, constipation, headache, fever, burns, back and muscle pains (AlOwaisi et al., 2014).

The seed essential oil contents of the two common Moringa species, i.e. M. oleifera and M. peregrina, are high, ranging from $33-41$ and $49.8 \%$, respectively. The seed oil obtained from Moringa has been used mainly in household as well as soap and perfume applications. Moringa seed oil has been evaluated as a potential feedstock for production of biodiesel and in industry as fine machine lubrication (Elsayed et al., 2016).

In addition, seeds contain a dimeric cationic proteins $(13 \mathrm{kDa})$ with coagulant and antimicrobial properties, and traditionally is utilized for purification and treatment of high turbid water (Anwar et al., 2007). Moringa gums, roots and seeds are widely used in traditional medicine and folk remedies for many diseases such as inflammation, cardiovascular and liver diseases, immune boosting agent, blood sugar and cholesterol regulator.

\subsection{Nutritional value of Moringa}

The plants belonging to Moringa species are rich in carotenes, flavonoids, sterols and tocopherols. Furthermore, Moringa species are rich in essential oils, antioxidants and sulfur amino acids (Elsayed et al., 2016). The young leaves of $M$. peregrina are rich in vitamins, minerals, proteins and low in fat and carbohydrates (Al-Owaisi et al., 2014).

The leaves are highly nutritious, and contain more vitamin A than carrots, more calcium than milk, more iron than spinach, more vitamin $\mathrm{C}$ than oranges and more potassium than bananas and more protein than milk and eggs. Moreover, leaves of Moringa species are rich in various phytochemicals like carotenoids, amino acids, sterols, glycosides, alkaloids, flavonoids, moringine, moringinine, phytoestrogens caffeoylquinic acids and phenolics. Fruits and seeds have been reported as a rich source of protein, essential elements $(\mathrm{Ca}, \mathrm{Mg}, \mathrm{K}$ and $\mathrm{Fe})$ and vitamins (vitamin $\mathrm{A}, \mathrm{C}$ and $\mathrm{E}$ ).
The seed oil contains all fatty acids contained in olive oil, except linoleic and was used as its acceptable substitute. In Egypt, the oil obtained from seeds of moringa trees were used as edible oil sources in south cost of Red Sea region (El Baky and El-Baroty, 2013).

\subsection{Phytochemistry of $M$. peregrine}

The main product derived from $M$. peregrina is seed oil, called 'ben oil'. The seed of M. peregrina contains about $50 \%$ oil. It is similar to the oil extracted from the seed of M. oleifera Lam.

A full chemical characterization of the seed oil displayed high levels of oleic and gadoleic acids and the main saturated acids were palmitic acid and stearic acid. $\beta$-sitosterol was found as the most predominant compound of the sterolic fraction of the oil and campesterol, stigmasterol and brassicasterol were also detected. $\alpha-, \gamma$ - and $\delta$ tocopherols, that are natural antioxidants were also found. The water purifying properties of the seed are caused by a protein which coagulates dispersed particles (Said-Al Ahl et al., 2017).

Elbatran et al. (2005) and Hajar and Gumgumjee (2014) are among studies concerning the phytochemical composition of $\mathrm{M}$. peregrina. Elbatran et al. (2005) studied the phytochemical and pharmacological properties of $\mathrm{M}$. peregrina and recognized the presence of four flavonoidal compounds isolated from the aerial parts; quercetin, quercetin-3-0- rutinoside (rutin), chrysoeriol-7-0-rhamnoside and 6,8,3,5tetramethoxy apigenin. The components showed anti-inflammatory activity.

Hajar and Gumgumjee (2014) isolated six compounds from the aerial parts of $\mathrm{M}$. peregrina: lupeol acetate, $\alpha$ - amyrin, $\beta$-amyrin, sitosterol, sitosterol-3-O-D-glucoside and apigenin which showed antibacterial activity.

\subsection{Biological properties of $M$. peregrine}

While $M$. oleifera has been traditionally utilized as a source of nutrients, studies displayed that different parts of the plant have essential biological properties. The leaves showed antioxidant and anticancer activities (Awodele et al., 2012), the bark and leaf extracts exhibited antimicrobial activities (Yusuf and Abdul Hamid, 2013), the pods have been traditionally used as a stimulating cardiotonic against fainting in Thailand, the seed 
extract was utilized to decrease lipid peroxidation, and the root was found to have anti-inflammatory activities. Recently, M. peregrina seed extracts showed antioxidant and anti-inflammatory properties (Elsayed et al., 2016).

Antimicrobial activities of $M$. peregrina oil extracted from seeds were fully studied. The oil had inhibitory effects on Staphylococcus aureus, Staphylococcus epidermidis, Pseudomonas aeruginosa, and Candida albicans (Alaklabi, 2015).

Both aqueous and ethanolic extracts of $M$. peregrina displayed anti-hyperglycemic effects on streptozotocin induced diabetes in rats by causing a significant reduction in blood glucose levels (ElAlfy et al., 2011).

\subsection{Induction of apoptosis and anticancer activity by $M$. peregrina on cancer cells}

The leaves extract of $M$. peregrina showed cytotoxic effect on HepG2 and MCF-7 cell lines while displaying low toxicity on the normal melanocytes cell line. Diethyl ether and ethyl acetate extract methods were highly effective for anticancer activity by inducing cell cycle arrest and apoptosis of the HepG2 cells by upregulation of p53, BAX, and Caspase-3 and downregulation of BCL-2. GC/MS analysis displayed that diethyl ether and ethyl acetate leaves extracts were rich in retinol, thymol, ascorbic acid, myristic acid, palmitic acid, and linoleic acid that would explain this activity (Mansour et al., 2019).

Also, the essential oil obtained from $M$. peregrina seeds has a significant inhibitory effect on different investigated cell lines. This effect was found to depend on the concentration used where HELA and HepG2 cells were the most affected cell types (Elsayed et al., 2016).

The ethanolic extract of the aerial parts of $M$. peregrina had a potent cytotoxic activity against two tested human cell lines; colon cancer cell line (HCT116) and breast cancer cell line (MCF-7) (ElAlfy et al., 2011).

Other studies revealed that treatment of HELA and PC-3 as well as CACO-2 cells with chloroform fraction of ethanolic extract of $M$. peregrina showed degraded DNA bands in the form of ladders, a typical indication of apoptosis, whereas the untreated control cells showed intact DNA bands when observed in UV transilluminator. Also, apoptosis was induced by upregulation of caspase3 mRNA and protein expression \& downregulation of mRNA expression of Bcl-2 in treated HELA and PC-3 as well as CACO-2 cells as compared to untreated cells \& decreasing in mRNA expression of Bcl-2 in HELA and PC-3 as well as CACO-2 cells, suggesting that chloroform fraction of ethanolic extract of $M$. peregrina induced HELA and PC-3 as well as CACO-2 cell death via the intrinsic pathway. The results from flow cytometry revealed that apoptosis could be induced after treatment of HELA and PC-3 as well as CACO-2 cells with chloroform fraction of ethanolic extract of M. peregrina as the numbers of early apoptotic cells and late apoptotic cells increased, supporting its direct antitumor activity (Abou-Hashem et al., 2019).

\section{Conclusion}

M. peregrina is a potential source of cytotoxic compounds. Oleic acid, palmitic acid, syringic acid, p-coumaric acid, vanillin, ferulic acid, naringenin, daidzein, quercetin and cinnamic acid may be responsible for the observed cytotoxicity of $M$. peregrina. Therefore, $M$. peregrina should be considered a candidate for therapeutic use alongside other medical tools in the treatment and management of cervical and prostate carcinoma. In addition to that, more research on the molecular mechanisms controlling induction of apoptosis and cell cycle arrest by different plant extracts needs to be performed. Studies on the safety, dosage and efficacy of plant extracts should be investigated.

\section{Acknowledgements}

The authors are very grateful to Egyptian International Pharmaceuticals Industries Company (EIPICO) for providing facilities to perform the work.

\section{Conflict of Interest}

The authors declare that there is no conflict of interest on this work. 


\section{References:}

Abou-Hashem, M. M. M., Abo-Elmatty, D. M., Mesbah, N. M. \& Abd El-Mawgoud, A. M., 2019. Induction of sub-G0 arrest and apoptosis by seed extract of Moringa peregrina (Forssk.) Fiori in cervical and prostate cancer cell lines. J. Integr. Med., 17, 410-422.

Al-Owaisi, M., Al-Hadiwi, N. \& Khan, S. A., 2014. GC-MS analysis, determination of total phenolics, flavonoid content and free radical scavenging activities of various crude extracts of Moringa peregrina (Forssk.) Fiori. leaves. Asian Pac. J. Trop. Biomed., 4, 964-970.

Alaklabi, A., 2015. Genetic diversity of Moringa peregrina species in Saudi Arabia with ITS sequences. Saudi J. Biol. Sci., 22, 186-190.

Anand, P., Kunnumakkara, A. B., Sundaram, C., Harikumar, K. B., Tharakan, S. T., Lai, O. S., Sung, B. \& Aggarwal, B. B., 2008. Cancer is a preventable disease that requires major lifestyle changes. Pharm. Res., 25, 2097-116.

Anwar, F., Latif, S., Ashraf, M. \& Gilani, A. H., 2007. Moringa oleifera: a food plant with multiple medicinal uses. Phytother. Res., 21, 17-25.

Ashkenazi, A., 2002. Targeting death and decoy receptors of the tumour-necrosis factor superfamily. Nat. Rev. Cancer, 2, 420.

Awodele, O., Oreagba, I. A., Odoma, S., Da Silva, J. A. \& Osunkalu, V. O., 2012. Toxicological evaluation of the aqueous leaf extract of Moringa oleifera Lam. (Moringaceae). J. Ethnopharmacol., 139, 330-6.

Bellail, A. C., Tse, M. C. L., Song, J. H., Phuphanich, S., Olson, J. J., Sun, S. Y. \& Hao, C., 2010. DR5-mediated DISC controls caspase-8 cleavage and initiation of apoptosis in human glioblastomas. J. Cell. Mol. Med., 14, 1303-1317.

El-Alfy, T. S., Ezzat, S. M., Hegazy, A. K., Amer, A. M. \& Kamel, G. M., 2011. Isolation of biologically active constituents from Moringa peregrina (Forssk.) Fiori.(family: Moringaceae) growing in Egypt. Pharmacogn. Mag., 7, 109.
El Baky, H. A. \& El-Baroty, G. S., 2013. Characterization of Egyptian Moringa peregrina seed oil and its bioactivities. Int. J. Manage. Sci. Bus. Res., 2, 98-108.

Elbatran, S. A., Abdel-Salam, O. M., Abdelshfeek, K. A., Nazif, N. M., Ismail, S. I. \& Hammouda, F. M., 2005. Phytochemical and pharmacological investigations on Moringa peregrina (Forssk) Fiori. Nat. Prod. Sci., 11, 199-206.

Elsayed, E. A., Sharaf-Eldin, M. A., El-Enshasy, H. A. \& Wadaan, M., 2016. In vitro assessment of anticancer properties of Moringa peregrina essential seed oil on different cell lines. Pakistan J. Zool., 48, 853-859.

Ghavami, S., Hashemi, M., Ande, S. R., Yeganeh, B., Xiao, W., Eshraghi, M., Bus, C. J., Kadkhoda, K., Wiechec, E. \& Halayko, A. J., 2009. Apoptosis and cancer: mutations within caspase genes. J. Med. Genet., 46, 497-510.

Giansanti, V., Torriglia, A. \& Scovassi, A. I., 2011. Conversation between apoptosis and autophagy:"Is it your turn or mine?". Apoptosis, 16, 321-333.

Hajar, A. S. \& Gumgumjee, N. M., 2014. Antimicrobial activities and evaluation of genetic effects of Moringa peregrina (forssk.) fiori. using molecular techniques. Int. J. Plant Anim. Environ. Sci., 4, 65-72.

Hanahan, D. \& Weinberg, R. A., 2011. Hallmarks of cancer: the next generation. Cell, 144, 646-674.

Karunamoorthi, K., Jegajeevanram, K. Vijayalakshmi, J. \& Mengistie, E., 2013. Traditional medicinal plants: a source of phytotherapeutic modality in resource-constrained health care settings. Evid. Based Complementary Altern. Med., 18, 67-74

Kaur, G. J. \& Arora, D. S., 2009. Antibacterial and phytochemical screening of Anethum graveolens, Foeniculum vulgare and Trachyspermum ammi. BMC Complement. Altern. Med., 9, 30.

Kravchenko, J., Akushevich, I. \& Manton, K. G. (2009). Cancer mortality and morbidity patterns in the US population: an interdisciplinary approach, Berlin: Springer. ISBN 0-387-78192-7. 
Li, Z. \& Sheng, M., 2012. Caspases in synaptic plasticity. Mol. Brain, 5, 15-15.

Mothana, R. A., Lindequist, U., Gruenert, R. \& Bednarski, P. J., 2009. Studies of the in vitro anticancer, antimicrobial and antioxidant potentials of selected Yemeni medicinal plants from the island Soqotra. BMC Complement. Altern. Med., 9, 7.

Ng, W. K., Yazan, L. S. \& Ismail, M., 2011. Thymoquinone from Nigella sativa was more potent than cisplatin in eliminating of $\mathrm{SiHa}$ cells via apoptosis with down-regulation of Bcl-2 protein. Toxicol. In Vitro, 25, 1392-8.

Ola, M. S., Nawaz, M. \& Ahsan, H., 2011. Role of Bcl-2 family proteins and caspases in the regulation of apoptosis. Mol. Cell. Biochem., 351, 41-58.

Ouyang, L., Shi, Z., Zhao, S., Wang, F. T., Zhou, T. T., Liu, B. \& Bao, J. K., 2012. Programmed cell death pathways in cancer: a review of apoptosis, autophagy and programmed necrosis. Cell prolif., 45, 487-498.

Palumbo, M. O., Kavan, P., Miller, W., Panasci, L., Assouline, S., Johnson, N., Cohen, V., Patenaude, F., Pollak, M. \& Jagoe, R. T., 2013. Systemic cancer therapy: achievements and challenges that lie ahead. Front. Pharmacol., 4, 57.

Pan, F., Pan, D., Pardoll, D. M., Barbi, J. \& Fu, J. 2019. Compositions and methods for targeting activin signaling to treat cancer. Google Patents.

Pan, S.-Y., Zhou, S.-F., Gao, S.-H., Yu, Z.-L., Zhang, S.-F., Tang, M.-K., Sun, J.-N., Ma, D.-L., Han, Y.-F., Fong, W.-F. \& Ko, K.-M., 2013. New Perspectives on How to Discover Drugs from Herbal Medicines: CAM's Outstanding Contribution to Modern Therapeutics. Evid.-Based Complement. Altern. Med., 2013, 627375-627375.
Rafieian-Kopaei, M., 2012. Medicinal plants and the human needs. J. Herbmed. Pharmacol., 1, 1-2.

Ramos, S., 2007. Effects of dietary flavonoids on apoptotic pathways related to cancer chemoprevention. J. Nutr. Biochem., 18, 427-442.

Said-Al Ahl, H. A., Hikal, W. M. \& Mahmoud, A. A., 2017. Biological Activity of Moringa peregrina: a Review. Am. J. Food Sci. Health, 3, 83-87.

Tiloke, C., Phulukdaree, A. \& Chuturgoon, A. A., 2016. The Antiproliferative Effect of Moringa oleifera Crude Aqueous Leaf Extract on Human Esophageal Cancer Cells. J. Med. Food, 19, 398403.

Wen, X., Lin, Z. Q., Liu, B. \& Wei, Y. Q., 2012. Caspase-mediated programmed cell death pathways as potential therapeutic targets in cancer. Cell prolif., 45, 217-224.

Wong, R. S., 2011. Apoptosis in cancer: from pathogenesis to treatment. J. Exp. Clin. Cancer Res., 30, 87.

Yan, N. \& Shi, Y., 2005. Mechanisms of apoptosis through structural biology. Annu. Rev. Cell Dev. Biol., 21, 35-56.

Yusuf, M. A. \& Abdul Hamid, T., 2013. Inhibitory activities of leave and bark extracts of Moringa oleifera lam against some medically important bacterial isolates. Int. J. Pharm. Sci. Inven., 2, 1216. 